This paper is part of the Proceedings of the $3^{\text {rd }}$ International Conference on Design,

\title{
Using Mass Flow Analysis (MFA) to estimate the performance of scenarios for a rainwater harvesting system in Tyseley, Birmingham, UK
}

\author{
D. V. L. Hunt , L. O. Makana \& C. D. F. Rogers \\ School of Civil Engineering, The University of Birmingham, UK
}

\begin{abstract}
Water is a precious natural resource and as populations grow the demand for its increased usage in many sectors is becoming widely apparent. Water Demand Management (WDM) has all too often been inwardly focussed and until recently has not considered sufficiently well the interdependencies that exist and loom large on the not too distant horizon (e.g. meeting rising mains water demands and wastewater removal requirements, whilst reducing pluvial related flood risk in peak storm events) storing up pinch-points for the future. The end-user is one area where changes to WDM can help to alleviate these problems through locally supplied water sources and provision of interim storage for rainfall.

This paper considers 175 scenarios for a RWH water supply system within the Tyseley Demonstrator project in Birmingham, UK, based upon 5 different years of rainfall data (2010 to 2014) and 35 variations in tank size, roof size and occupancy rates. Findings show that depending on these ranges of local conditions a RWH system has the potential to reduce 'Annual Mains Water' inflow by $4.3 \%$ to $18.0 \%$ and 'Annual Storm Water' outflow by $34 \%$ to $100 \%$.

Keywords: rainwater harvesting, water demand management, pluvial flood risk.
\end{abstract}

\section{Introduction}

Tyseley is located in the south eastern half of Birmingham, bordering Small Heath and Yardley. The area consists of 230 businesses (employing in excess of 5000 people) including Webster and Horsfall (one of the oldest cable industries that laid the first wired communications across the Atlantic); school (Redhill); College; railway station with museum; Grand Union Canal Wharf; Energy from Waste facility (incinerating 350,000 tonnes/yr) and an Energy Park (BCC [1]). "The 
vision for Tyseley is an Environmental Enterprise District (EED) as the principal location in Birmingham for $\mathrm{CO}_{2}$ reduction as part of a low carbon, low waste economy through encouraging recycling, energy production and renewables including manufacturing and supply chain development" (BCC [1], p. 2). Whilst this is primarily focussed on energy there is an appreciation by Severn Trent (the local water provider) that there is a need to provide a community-scale living laboratory to demonstrate the practicality and benefits of combined water reuse and sustainable drainage in order to stimulate innovation and commercialisation of UK water technology and to raise public awareness and support for more sustainable living. The Birmingham 'Water' Demonstrator looks to provide local enhancements to existing green infrastructure and tangible improvements to a river corridor. Therein it will monitor measure and evaluate the costs and benefits (i.e. physical, financial, environmental, health and wellbeing) over a five-year period (Brewington [3]). This paper forms part of preliminary research looking at potential performance for a range of localised water supply options (in this case RWH) taking into account local context and conditions for Tyseley (Figure 1).

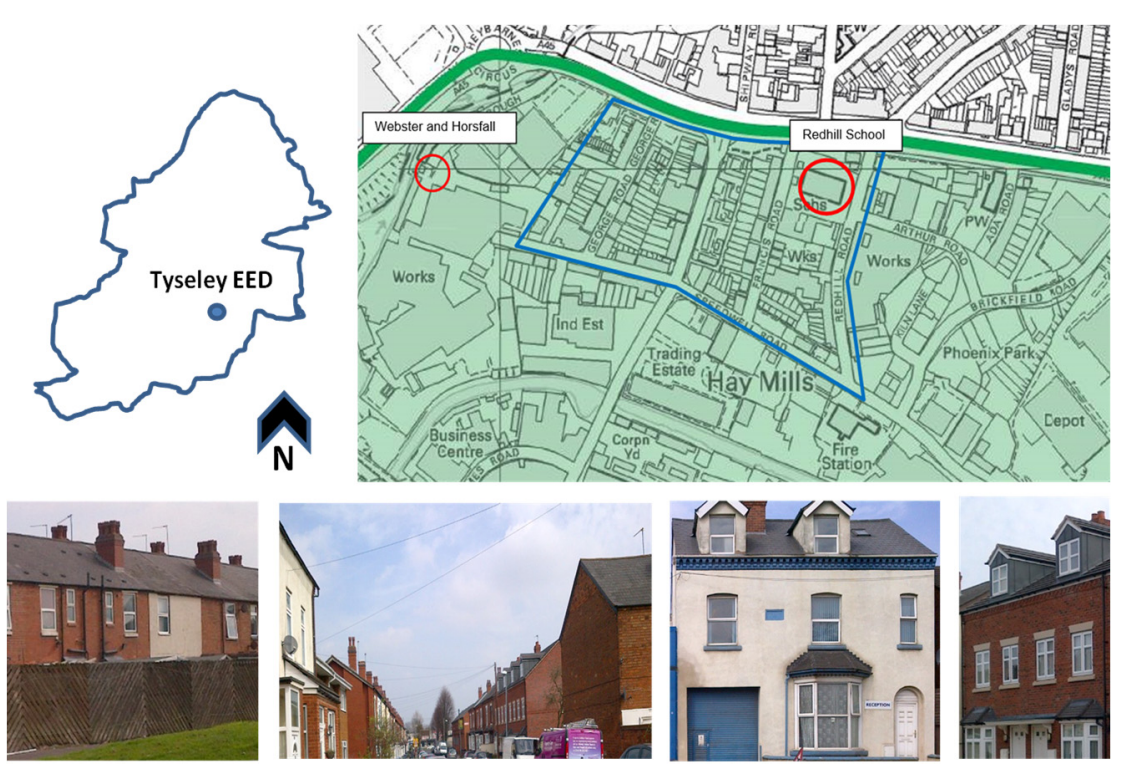

Figure 1: Tyseley EED location map showing typical dwellings.

\section{Methodology}

Step 1: Define household water demands appropriate to Tyseley - for an individual and for a household (Section 2.1);

Step 2: Investigate whether RWH could be adopted as a potential water supply source at household level.

- $\quad$ Conduct an MFA;

- Identify influential variables likely for Tyseley (Section 2.2). 
Step 3: Perform a parametric scenario(s) study using Mass Flow Analysis (MFA) for RWH supply options within the Tyseley area, considering:

- Annual Mains Water Reduction (\%) - inflow;

- Annual Storm Water Reduction (\%) - outflow;

- Annual Waste Water Reduction (\%) - outflow.

In order for the analyses to be meaningful and to best reflect likely performances in the Tyseley area a total of 175 scenarios are considered with:

- 1 (constant) value for water demand (Section 2.1);

- 1 RWH option for water supply (Section 2.2);

- 5 years of daily (variable) rainfall data, 2010-14 (Section 2.3);

- $\quad 35$ variations in tank/roof size \& occupancy rate (Section 2.4).

Step 4: Present and discuss results (Section 3.0):

\subsection{Water demands}

The water demands (litres per person per day) shown in Table 1 were assumed for domestic properties in Tyseley based on the work of Zadeh et al. [13]. A sensitivity analysis of socio-technological influences has been investigated previously by Zadeh et al. [14] and is beyond the scope of this research. The household demand for every occupant is assumed identical and therefore the only influencing factor in household demand is occupancy rate (which is assumed to vary from 1 to 5 for Tyseley); these are shown in Table 2. This paper assumes a linear relationship between non-potable demands and occupancy with the proviso that it must be appreciated that subtle changes can exist (EST [5], Bello-Dambatta et al. [2]), however, they are not considered as variables here.

Table 1: $\quad$ Household water demands (modified from Zadeh et al. [13]).

\begin{tabular}{|c|c|c|c|}
\hline $\begin{array}{c}\text { Conventional } \\
\text { water supply } \\
\text { source(s) } \\
\end{array}$ & Water use & $\begin{array}{c}\text { Total water } \\
\text { demand } \\
(l / p / d a y) \\
\end{array}$ & $\begin{array}{c}\text { Conventional } \\
\text { fate of } \\
\text { stream(s) } \\
\end{array}$ \\
\hline From mains & Dishwasher & 3.6 & to sewer \\
\hline From mains & Sink & 10.4 & to sewer \\
\hline From mains & Washing machine & 27.3 & to sewer \\
\hline From mains & Shower & 52.4 & to sewer \\
\hline From mains & Bath & 25.3 & to sewer \\
\hline From mains & Hand basin & 1.6 & to sewer \\
\hline \multirow[t]{2}{*}{ From RWH } & $\mathrm{W} / \mathrm{C}$ & 26.5 & to sewer \\
\hline & TOTAL & 147.1 & \\
\hline
\end{tabular}


Table 2: Household water demands.

\begin{tabular}{|c|c|c|c|}
\hline $\begin{array}{c}\text { Occupancy } \\
\text { rate }\end{array}$ & $\begin{array}{c}\text { Daily household } \\
\text { demand } \\
\text { (litres/day) }\end{array}$ & $\begin{array}{c}\text { Yearly household } \\
\text { demand } \\
\text { (litres/day) }\end{array}$ & $\begin{array}{c}\mathbf{5 \%} \text { household } \\
\text { demand } \\
\text { (litres) }\end{array}$ \\
\hline 1 & 147.1 & 53692 & 2685 \\
\hline 2 & 294.2 & 107383 & 5369 \\
\hline 3 & 441.3 & 161075 & 8054 \\
\hline 4 & 588.4 & 214766 & 10738 \\
\hline 5 & 735.5 & 268458 & 13423 \\
\hline
\end{tabular}

\subsection{RWH water supply option}

When it rains within a household boundary (this includes house and garden) this water either infiltrates directly into the ground until saturated ( $\mathrm{X}$ in Figure 2 ) or hits impermeable surfaces (i.e. rooftops, paths and driveways) and runs-off into the storm water system ( $\mathrm{Y}$ and $\mathrm{Z}$ in Figure 2). Rainwater harvesting (RWH) systems capitalise on this local supply of water by redirecting rainwater from rooftops into a storage tank subsequently using it to meet non-potable demands (e.g. toilet flushing and garden irrigation) either partially or fully ( $\mathrm{a}$ in Figure 2).

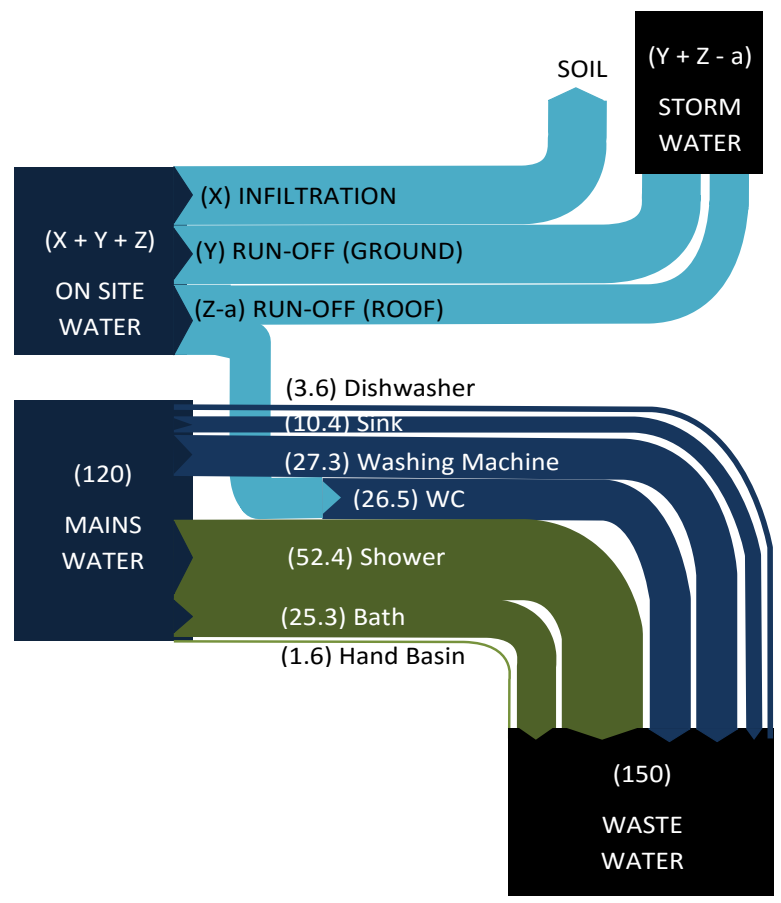

Figure 2: MFA of domestic RWH showing inflows and outflows (1/person/day). 
The advantage of a RWH system based upon an MFA analysis for a single occupant (Figure 2) is that the requirement for mains water (and related carbon emissions) can be reduced by $18.1 \%$ when WC demands alone are met through rainwater. However, the overall temporal performance of RWH systems is influenced by rainfall events (Section 2.3), roof size, filtration systems (including skimmer overflow and backflow valve, with inlet calming), tank size (Section 2.4) and the dynamics of this filling and emptying (Roebuck [11]). These factors influence the supply demand balance and the amount of rooftop run-off that enters (or not) the storm water system (Hunt and Rogers [8]).

\subsection{Rainfall}

Accurate rainfall data is important as it influences RWH tank sizing (Section 2.4) and therefore the supply/demand balance (Section 2.5). Therefore, five years of rainfall data (2010 to 2014, Table 3) for Coleshill (circa 7 miles from Tyseley) have been adopted for RWH calculations (Table 3). This rainfall data was collected by the Met Office and can be found in the National Meteorological Archive. Rainfall is typically collected via an automated Tipping Bucket Rain

Table 3: Average rainfall data over five years.

\begin{tabular}{|c|c|c|}
\hline Year & $\begin{array}{c}\mathbf{A}=\text { Yearly averages } \\
(\mathrm{mm} / \text { day })\end{array}$ & $\begin{array}{c}\mathbf{B}=\text { Daily average } \\
\text { values }=\mathbf{A} / \mathbf{3 6 5} \\
(\mathrm{mm} / \text { day })\end{array}$ \\
\hline 2010 & 537.9 & 1.5 \\
\hline 2011 & 425.4 & 1.2 \\
\hline 2012 & 863.7 & 2.4 \\
\hline 2013 & 594.9 & 1.6 \\
\hline 2014 & 789.3 & 2.2 \\
\hline & $\begin{array}{c}\text { Average }= \\
\mathbf{6 2 4} \mathbf{m m} / \mathbf{y r}\end{array}$ & $\begin{array}{c}\text { Average }= \\
\mathbf{1 . 7 m m} / \mathbf{d a y}\end{array}$ \\
\hline
\end{tabular}

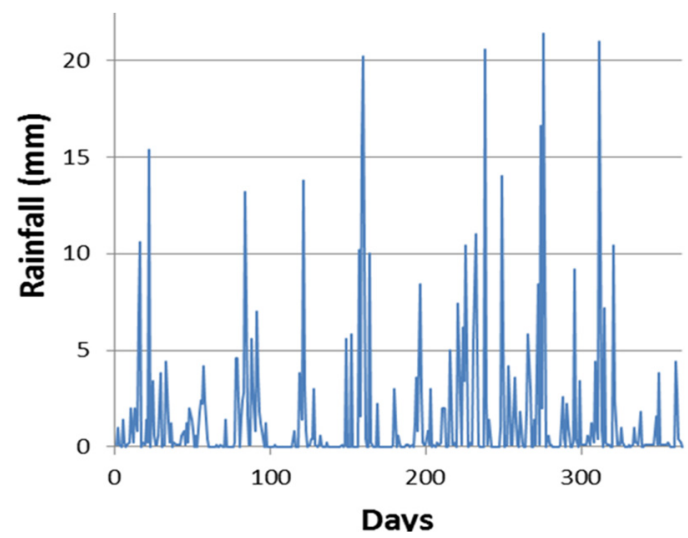

Figure 3: Impact of RWH on daily water inflows in 2010 (1/person/day). 
Gauge (TBRG) providing digital half-hourly data outputs for actual rainfall (mm) and rate of rainfall $(\mathrm{mm} / \mathrm{hr})$. For the purposes of this research daily values (Figure 3) are deemed to be more than adequate for a baseline estimation of potential rainwater supplies.

\subsection{Roof size and tank size}

The following assumptions appropriate to Tyseley's Urban Form were adopted for the RWH system:

i. $\quad$ Roof type = steep tiled roofs (walkover survey of site, see Figure 1);

ii. $\quad$ Roof area $=30$ to $120 \mathrm{~m}^{2}$ (walkover survey of site, see Figure 1);

iii. $\quad$ Tank size $=700$ to 2900 litres (see Figure 4). Sized according to BS8515, the lesser of $5 \%$ annual rainfall collected (the average value over five years is used - Table 3 ) and 5\% water demand. The 35 scenarios adopted within this paper, which vary with occupancy and roof area, are shown in Table 2.

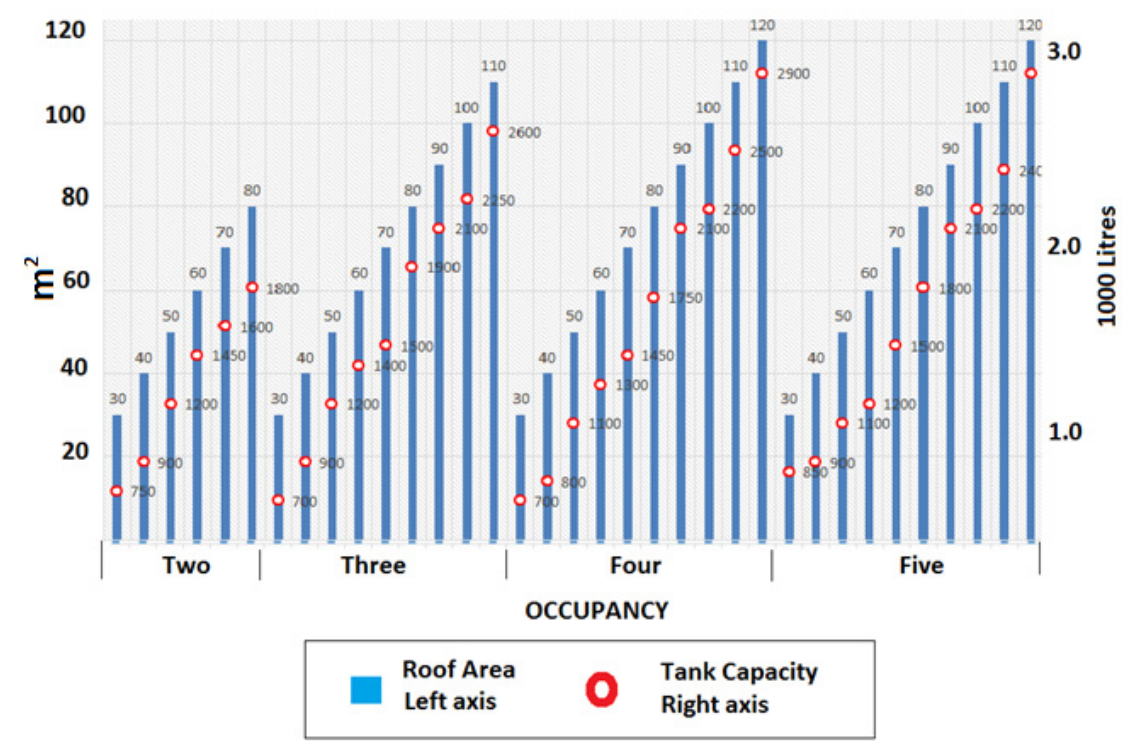

Figure 4: Tank sizes, roof areas and occupancy rates within scenarios.

\subsection{Matching supply with demand}

The amount of water that can be used each day depends on the availability of water from the rainwater tank. The water volume within the tank will vary daily and the rate at which the tank empties and fills dictates how (and if) daily demands are met. Potential rainwater supply volumes are calculated according to Equation (1).

$$
Q_{t}=R_{t} \cdot A \cdot\left(Z_{1} \cdot Z_{2} \cdot Z_{3}\right)
$$


where:

$Q_{t}=$ Flow into RWH tank in time t (litres);

$R_{t}=$ Average rainfall in time $t(\mathrm{~mm})$;

$A=$ Plan surface area of the roof $\left(\mathrm{m}^{2}\right)$;

$Z_{1}=$ Coefficients for roof pitch (dimensionless);

$Z_{2}=$ Coefficients for material type (dimensionless);

$Z_{3}=$ Coefficients for filter (dimensionless);

$R_{t}$ is the total accumulated rainfall in a single time step. $\mathrm{t}$ is calculated on a daily basis using 365 separate time steps (i.e. from $t_{0}$ to $t_{364}$ ). In total of 1825 time steps are used over for the $5 \mathrm{yr}$ period considered. It is assumed that not all the rainwater that falls is collected. In this paper assessment losses are assumed to occur from a pitched $\left(Z_{1}=0.9\right)$ tiled $\left(Z_{2}=0.95\right)$ roof with in line filters $\left(Z_{3}=0.95\right)$. In other words, $81 \%$ of the rainfall volume falling on the roof is successfully collected for re-use (Woods-Ballard et al. [12]). Both aspects rely on a water balance equation, adapted from McMahon et al. [9].

$$
V_{t}=V_{t-1}+Q_{t}-D_{t}
$$

Subject to $0 \leq V_{t} \leq \mathrm{S}$, where:

$V_{t}=$ Stored water in RWH tank at time $t$ (litres);

$V_{t-1}=$ Stored water in RWH tank in time $t$ - 1 , i.e. stored water volume from previous day (litres);

$Q_{t}=$ Flow into the RWH tank in time t (litres);

$D_{t}=$ Non-Potable demand in time $\mathrm{t}$ (litres);

$S=$ Useable RWH tank volume (litres).

A 'yield-before-spillage' approach is adopted (Mitchell [10], Roebuck [11], Hunt et al. [6], Hunt and Rogers [7, 8]) and spillage (i.e. overflow) occurs once S is exceeded. The total yearly overflow $O_{h h}$ per household $(1 / \mathrm{hh} / \mathrm{yr})$ for the RWH tank is the sum of the daily spillages. No leakage or evaporation losses are assumed within the tank itself (it is essentially a sealed underground unit, Chu et al. [4]). In essence therefore this means when daily inflows are insufficient to meet daily non-potable demands, water levels 'drawdown' will occur within the RWH tank and where daily inflows are more than sufficient to meet daily non-potable demands a 'topping up' will occur. If the RWH tank is empty or to be more precise the extractable volume is zero, then no draw down can occur. In such cases the demands will be met through mains water. (N.B. A RWH tank will never empty as a 'reserve' is maintained to ensure the pump remains submerged.) When the tank is filled any overflow passes into the mains storm water system or alternatively to a combined sewer system adding to pluvial flood risk or combined sewer overflow risk. Where sufficient 'empty' storage space (or holding capacity) occurs within the tank this pluvial flood risk can be reduced. Figure 5 shows a typical response of the RWH tank during a 365-day period. These plots were recorded for all scenarios but, are not shown within the confines of this paper; instead the results are summarised over each year considered. 


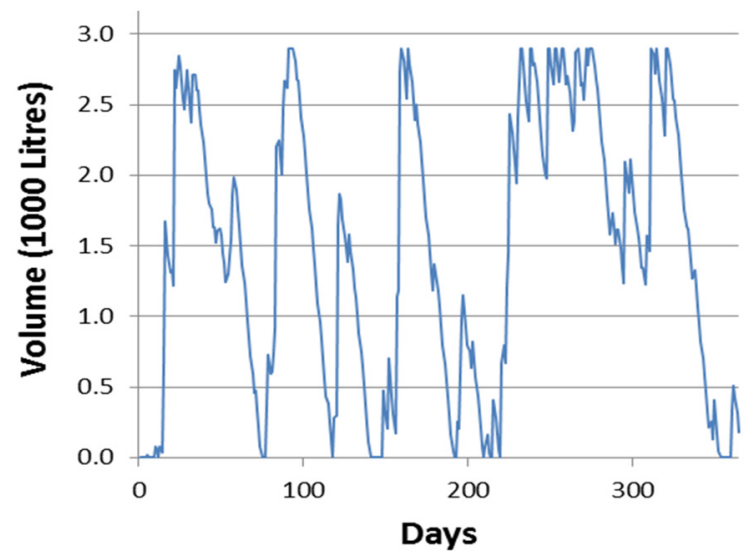

Figure 5: Typical response of tank as it fills and empties (the year is 2010, a 2900-litre tank, $120 \mathrm{~m}^{2}$ roof and 5 occupants).

\section{Results}

From Figure 6 it can be seen that there is a clear correlation between roof area and annual mains water reduced. Provided the demands remain unchanged then an increase in roof area leads to an increase in the amount of 'Annual Mains Water Reduction \%'. This is because more rainwater can be collected, treated and reused in order to meet demands previously met by mains water. In addition, there is a clear correlation between household occupancy and annual mains water reduced. In other words provided the roof area is unchanged then any increase in household occupancy results in a decrease in 'Annual Mains Water Reduction \%'. This is because demands are being increased and yet available RWH supplies remain unchanged. When considering all five years 'Annual Mains Water Reduction \%' varied from $4.3 \%$ to $18.0 \%$ The former occurred in one case in 2011 with 5 occupants and $30 \mathrm{~m}^{2}$ roof area, the latter occurred in $20 \%$ (i.e. $7 / 35$ ) of cases: in 2012 with 2 occupants, $\geq 80 \mathrm{~m}^{2}$ roof area; and in 2014 with 2 occupants and $\geq 60 \mathrm{~m}^{2}$ roof area, 3 occupants and $\geq 100 \mathrm{~m}^{2}$ roof area, 4 occupants and $\geq 120 \mathrm{~m}^{2}$ roof area).

In terms of 'Annual Storm Water Reduction \%' this was found to vary from $34 \%$ to $100 \%$, the former occurred in one case in 2012 with 5 occupants, $30 \mathrm{~m}^{2}$ roof area, while the latter occurred in $13 \%$ (i.e. $23 / 175$ ) of cases $-1 / 35(3 \%)$ in $2010 ; 20 / 35(57 \%)$ in $2011 ; 0 / 35(0 \%)$ in $2012 ; 1 / 35(3 \%)$ in 2013 ; and $1 / 35(3 \%)$ in 2014. Interestingly if the tank had been sized 3 times larger than required by BS8515 then $100 \%$ could have been achieved in almost all cases (even in peak events) in all years - this is in line with the findings of Hunt and Rogers [7].

A RWH system has no impact on the waste water stream and therefore, no impact on 'Annual Waste Water Reduction \%' for any occupancy and roof size. This is because the same amount of water is being used within the household and therefore the same amount of wastewater is being produced (irrespective of occupancy and roof size). The same is not true of a greywater system. 

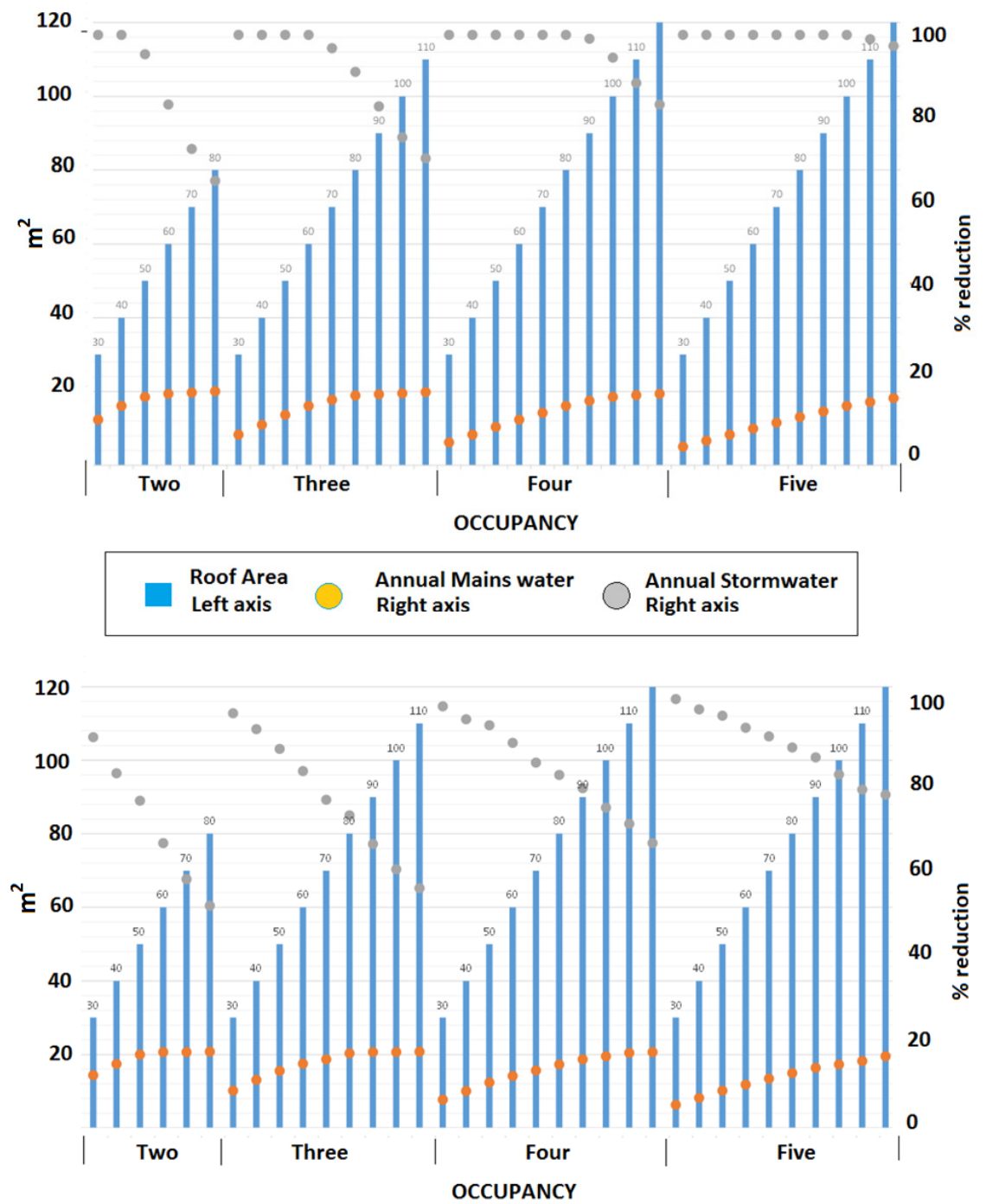

Figure 6: Annual mains water and storm water reduction according to roof areas and occupancy rates - for tank size see Figure 4. (Results are shown for 2011 (top) and 2010 (bottom).)

\section{Concluding discussion}

By considering 175 scenarios for RWH water supply systems within the proposed Tyseley Demonstrator project in Birmingham, UK, it has been demonstrated through the use of MFA that there is the potential to reduce 'Annual Mains Water' 
flows within domestic properties by between $4.3 \%$ and $18.0 \%$ and 'Annual Storm Water' flows by between $34 \%$ and $100 \%$. These results have critical implications in terms of actual water supply options that might be considered for the Tyseley demonstrator project and highlights the fact that any variability in local conditions (e.g. occupancy rate (1 to 5); rainfall (2010 to 2014); tank size (700 to 2900 litres) and roof size (30 to $\left.120 \mathrm{~m}^{2}\right)$ ) will significantly impact on RWH performance. This is even more important when considering the short- and long-term (i.e. far future) changes in flows that can occur and will undoubtedly be influenced by changes in user behaviour and technological efficiency (both in isolation and combination). The proposed 5-year monitoring will help to understand some of these aspects more clearly in addition to highlighting the differences between predicted and actual flow performance within a live demonstrator project.

That said there are many other considerations that must be made when assessing the wider impacts of modified flows as a result of water supply interventions such as RWH in areas such as Tyseley. For example, what would be the implications (in terms of flows and performance) for man-made mains infrastructure systems that feed clean water into (and take water away from) domestic properties? Would their functionality be impacted by such interventions? In addition, what would the implications be for natural systems (e.g. rivers/flood plains) that are ultimately impacted by these inflows/outflows, not least if adoption became more widespread following a successful demonstrator initiative?

\section{Acknowledgements}

The authors wish to thank Severn Trent Water and The University of Birmingham (FCFC GAE 1391 and FCFC GBH 1029) who funded this research. In addition, the authors would like to thank the Engineering and Physical Sciences Research Council for their support under the Liveable Cities (EP/J017698) Programme Grant providing the thinking upon which this research has been based.

\section{References}

[1] BCC (2011) Tyseley Environmental Enterprise District: A framework for action. Birmingham City Council, Birmingham, UK, 12 pages.

[2] Bello-Dambatta, A., Kapelan, Z., Butler, D., Oertlé, E., Wintgens, T., Rozos, E., Makropoulos, C., Mamassis, N. Transitions to the Urban Water Services of Tomorrow (Trust D42.1) Guidance on evaluation and selection of sustainable water demand management technologies, European Union Seventh Framework Programme (FP7/2007-2013), EU, 2014.

[3] Brewington, J. (2015). The Tyseley Urban Demonstrator. http:/www.sustainabilitywestmidlands.org.uk/wp-content/uploads/UrbanDemonstrator-Tyseley-Birmingham-Science-City.pdf

[4] Chu, S.C., Liaw, C.H., Huang, S.K., Tsai, Y.L. \& Kuo, J.J. (1999) The study for influencing factors of urban rainwater catchment system capacity. Proc. of 9th International Rainwater Catchment Systems Conference, Petrolina, Brazil. 
[5] EST (2013). At home with water. Energy Savings Trust London UK, 2013.

[6] Hunt, D.V.L., Lee S.E., Leach, J.M., Bouch, C.J. and Rogers C.D.F. (2014). Urban Metabolism Assessment of Liveable Future UK Cities. Proceedings of the 4th World Sustain. Forum, 1-30 November 2014. Sciforum Electronic Conference Series, Vol. 4, 2014. doi: 10.3390/wsf-4-f010.

[7] Hunt, D.V.L. and Rogers, C.D.F. (2014a) A Benchmarking system for Domestic Water Use. Sustainability, 6, 2993-3018; http://doi:10.3390/ su6052993.

[8] Hunt D.V.L. and Rogers C.D.F. (2014b) Rainwater harvesting: Trade-offs between pluvial flood risk alleviation and mains water resource savings Proceedings of the 4th World Sustain. Forum, 1-30 November 2014. Sciforum Electronic Conference Series, Vol. 4, 2014. http://doi:10.3390/ wsf-4-a006.

[9] McMahon, T.A., Pegram, G.G.S., Vogel, R.M., Peel, M.C. Revisiting reservoir storage-yield relationships using a global streamflow database. Advances in Water Resources. 2007, 30, 1858-1872.

[10] Mitchell, V.G. How important is the selection of computational analysis method to the accuracy of rainwater tank behaviour modelling? Hydrol. Process. 2007, 21, 2850-2861.

[11] Roebuck, R.M. A Whole Life Costing Approach for Rainwater Harvesting Systems. Ph.D. Thesis, University of Bradford, Bradford, UK, 17 July 2007.

[12] Woods-Ballard, B., Kellagher, R., Martin, P., Jefferies, C., Bray, R., Shaffer, P. The SUDS manual; (CIRIA): Report C697, London, UK, 2007.

[13] Zadeh, S.M., Hunt, D.V.L., and Rogers C.D.F. (2014). Socio-Technological Influences on Future Water Demands. Water. 6 1961-1984; http://doi:10.3390/w6071961.

[14] Zadeh, S.M., Hunt, D.V.L., Lombardi, D.R., and Rogers C.D.F. (2014). Carbon costing for mixed-use greywater recycling systems. Proc. Institute of Civil Engineers: Water Management, 167 (8), 467-481 http://dx.doi.org/ 10.1680/wama.12.00093.

[15] Zadeh, S.M., Hunt, D.V.L., Lombardi, D. R., and Rogers C.D.F. (2013). Shared Urban Greywater Recycling Systems: Water Resource Savings and Economic Investment. Sustainability, 5 5(7), 2887-2912; http://dx.doi.org/ $10.3390 /$ su5072887. 